\title{
XCII. Experiments on the combination of acetic acid and alcohol with volatile oils
}

\section{Vauquelin}

To cite this article: M. Vauquelin (1822) XCII. Experiments on the combination of acetic acid and alcohol with volatile oils, Philosophical Magazine Series 1, 59:290, 451-453, DOI: $10.1080 / 14786442208652773$

To link to this article: http://dx.doi.org/10.1080/14786442208652773

册 Published online: 29 Jul 2009.

Submit your article to this journal $\sqsubset \pi$

Џ Article views: 2

Q View related articles $\square$ 
TABLE II.

Corrections of $\mathrm{B}$ and $\mathrm{C}$.

\begin{tabular}{|c|c|c|}
\hline \multirow{2}{*}{$\begin{array}{l}\text { Argument }= \\
\text { N.P.D. of the } \\
\text { Pole-Star. }\end{array}$} & \multicolumn{2}{|c|}{ Mrultiplier of } \\
\hline & $\mathrm{B}$ & $\mathrm{C}$ \\
\hline $1^{\circ} .37^{\prime} .50^{\prime \prime}$ & .997 & .995 \\
\hline 40 & $\cdot 993$ & .990 \\
\hline 30 & .990 & .985 \\
\hline 20 & .996 & .980 \\
\hline 10 & .983 & .975 \\
\hline 1.37 .0 & $\cdot 980$ & .970 \\
\hline 1.36 .50 & .976 & .965 \\
\hline 40 & .973 & .960 \\
\hline 30 & .970 & .955 \\
\hline 20 & .966 & .950 \\
\hline 10 & .963 & .945 \\
\hline $1,36.0$ & $\cdot 960$ & $\cdot 940$ \\
\hline 1.35 .50 & .957 & .935 \\
\hline 40 & .953 & .930 \\
\hline 30 & .950 & .926 \\
\hline 20 & $\cdot 946$ & .921 \\
\hline 10 & .943 & .916 \\
\hline 1.35 .0 & .940 & -yłl \\
\hline
\end{tabular}

XCII. Experiments on the Combination of Acelic Acid and Alcoliol with volatile Oils. By M. Vauquelin *.

Exp. 1.- Eighty parts of volatile oil of lavender were mixed with 80 parts of acetic acid; the areometer at $10^{\circ}$. After shaking the mixture smartly for a considerable time to perfect the union of the two liquids, it was left to settle. When again examined and separated, the oil was found to occupy 125 parts, and the acid only occupied 35 ; the latter had therefore lost 45 parts, and the oil had acquired 45 parts.

Exp. 2.-Eighty parts of the same oil were joined to the 35 parts of acetic acid remaining, and after mixing and separating as in the preceding experiment, the oil was found to occupy 115 parts, and the acid was recluced to 5 : so that this time the 80 parts of oil absorbed only 30 parts of acid.

* From the Aunales de Chimie for March 1822. $3 \mathrm{~L} 2$ 
I think that if the oil has only absorbed this time 30 parts of acid in place of 45 , it is owing probably to the acid having become more aqueous, and therefore less fit for mixing with the oil. Of the 100 parts of acetic acid employed for this experiment, there were six parts which conld not combine with the oil. This remnant of the acid had acquired a yellow colour : its taste was still very acid, and its odour indicated that it contained much oil. In fact, when a drop of this acid was put in water, it fell to the bottom, and the oil separated and mounted to the surface.

In this experiment, the acetic acid and oil formed two compounds of unequal proportions; one in which there was an excess of oil, the other in which there was more acid than oil. It appears from this experiment, that 100 parts of oil of lavender can absorb 56 parts of acetic acid; but as the portion of vinegar which remains, holds in solution a certain quantity of oil not easy to be estimated, it may be concluded that 50 parts of vinegar will saturate 100 of oil, that is to say, one portion of acid for two portions of oil.

Exp. 3.-To know if water could separate acetic acid from oil, 50 parts of the compound richest in oil, and 55 parts of water, were well shaken together for a long time. It was then found that the bulk of the oil was reduced to 35 , while that of the water had been augmented 15: the oil however was still acid ; in fact, it contained three parts of acetic acid.

Twenty parts of the same compound were shaken with 80 parts of water; the oil on settling had lost eight, and the water was augmented in the same proportion. In this experiment, the water had abstracted from the oil the whole of the acid which it contained, and had absorbed also a little oil, since the 20 parts of the compound contained but $7 \cdot 2$ of acid, and there was a loss of 8 .

When the acetic acid is pure, the oil can ausorb it entirely; but if it contains a portion of water, were it only 5 per cent., a part will remain which the oil cannot seize upon; so that the part of the acetic acid which does not combine with the oil, contains necessarily a greater quantity of water than vinegar previous to the operation.

This property which viuegar possesses, of combining with volatile oil, ought not to canse any surprise, for it is well known with what facility this acid imbibes the odours of plants.

Effects nearly similar are produced when camphor is dissolved in nitric acid, and also in acetic acid ; that is to say, the camphor seizes on the pure part of the acids, and leaves another watery portion which was previously conbined with the whole 
of the acid. The greater the quantity of camphor, the less is the portion of acid remaining with the water; the latter contains also a small quantity of camphor, but that which water cannot separate : this quantity of camphor ought to be nearly the same as that which remains in the acidulated water, when oil of camphor is decomposed by water.

These effects are not confined to greasy bodies and to acids; they occur equally between alcohol and these same greasy bodies.

Having long ago been applied to by the Regie des Octrois de Paris, to know whether it be possible to introduce under colour of essences, turpentine for example, a certain quantity of alcohol (a fraud which can only be effected by the manufacturers of varnishes), I made on this subject some experiments, which proved to me that a certain quantity of alcohol can be mixed with essences, withcut our being able to detect it by the ordinary means, because, as long as the bulk of alcohol does not exceed that of oil, the mixture or combination will not be disturbed by water, and the odour will be masked by that of the essence which is strongest.

I have repeated lately some of these experiments; the following are the results:

Exp. 1.-100 parts of volatile oil of turpentine and 20 parts of alcohol mixed together, did not separate on being left to settle, and formed a homogeneous body : this effect is produced by the solution of the alcohol in the oil ; for one portion of alcohol cannot dissolve five parts of oil.

Exp. 2.- The above mixture, shaken for a long time, and at intervals with water added, was reduced to 103 . The water had therefore abstracted 12 parts of alcohol from the oil, and the oil had preserved 8 .

Oil of turpentine may therefore contain a twelfth of its bulk of alcohol without its being liable to be perceived, unless it be through the specific gravity, which is a little diminished: however, if the lotions are repeated enough, the whole of the alcohol may be at last separated from the oil.

The mixture or combination of 100 parts of oil of turpentine, and 20 parts of alcohol, is not disturbed by water; but when poured upon water aud slightly agitated, a portion of the alcohol will be seen to detach itself, and to form, in uniting with the water, some very marked streaks. 